\title{
DAS VORKOMMEN VON BOTRYTIS ANTHOPHILA BOND. IN PROBEN VON HANDELSSAATGUT FINNISCHEN ROTKLEES
}

\author{
Arvi Salonen \\ Pflanzenpathologisches Institut der Universität Helsinki
}

Im Jahre 1913 fand man in Russland einen Pilz, der die Staubbeutel von Rotklee vernichtete. Bondarcev (4) isolierte und beschrieb das Pathogen und gab ihm den Namen Botrytis anthophila. Danach wurde festgestellt, dass B. anthophila Bond. nicht nur in Russland $(6,7,13)$, sondern auch anderwärts in Europa $(10,3,12,2)$ häufig vorkam. In den USA fand man die Krankheit im J. 1948 (5). Synonyme $B$. antherarum trifolii Schlecht sowie B. trifolii van Beyma $(12,9)$.

B. anthophila ist ein durch die Saat verbreitetes Pathogen $(4,13,12,11$ u.a.). Die erkrankte Pflanze entwickelt sich im übrigen normal, aber im Blütestadium ist wahrzunehmen, dass die Staubbeutel aller Blüten der Blütenstände vernichtet sind. Der anfangs interzellular gewachsene Pilz bildet in den Staubbeuteln seine Konidienträger und eine graue Konidienmasse. Die bestäubenden Insekten, Hummeln und Bienen $(13,12)$ sowie nach Sigrianski und Minyaeva (11) auch Apion-Arten, befördern Sporen des Pilzes auf gesunde Blütenstände. Die Sporen keimen in der Narbe des Fruchtblattes; die Hyphen dringen in die Samenanlage ein und bilden ein Dauermyzel, das sich im Samen erhält. Während der Pilz keimt, bildet er Konidien (9). Das Myzel dringt in alle Teile der wachsenden Pflanze ein, aber Konidienbildung erscheint nur in ihren Staubbeuteln $(4,12,10)$.

Nach der heutigen Auffassung (12) sind Wirtspflanzen von B. anthophila nur wilder und angebauter Rotklee. Zwar hat man unter Samen von Weissklee einen an B. anthophila erinnernden Pilz gefunden, aber nach NoBLE (9) handelt es sich dabei um ein Konidienstadium von Sclerotinia spermophila.

$B$. anthophila ist von nachteiliger Wirkung auf die Samenerzeugung der Wirtspflanze. So hat nach BergSTRöm (2) in einem Falle die Infektion des Pilzes ein Fallen der Fertilität von $80 \%$ auf $5.5 \%$ bewirkt. Meier \& Krivoduskaja (8) und Aleshina (1) haben vorbereitende Untersuchungen über die Möglichkeiten chemischer Bekämpfung von B. anthophila ausgeführt. Die Krankheit hat durch Behandeln 
der befallenen Samen mit einem Kulturfiltrat von Trichoderma lignorum bekämpft werden können; dagegen haben TMT-Präparate auf sie nicht einzuwirken vermocht können (1).

Uber das Vorkommen von B. anthophila in Finnland liegen vorläufig keine Schrifttumsbelege vor. Da aber zu erwarten war, dass der Pilz auch hier vorkäme, wurden 50 Samenproben untersucht, die durch Vermittlung der Staatlichen Samenkontrollanstalt aus verschiedenen Gegenden erhalten worden waren; die Proben waren Ertrag vom Jahre 1957.

Den Samen $(4 \times 50$ Samen $)$ breitete man in Petrischalen aus, auf steriles Filtrierpapier, unter dem sterilisiertes Wasser-Agar-Gelee (2\%) lag; das daraus verdunstende Wasser hielt das Keimsubstrat feucht. Das Keimen ging in einer Temperatur von etwa $+20^{\circ} \mathrm{C}$ vor sich.

Aus Rotkleesamen wurde B. anthophila auf Difco-Sabourad-Maltose (SM)-Agar isoliert. Die Messungen beziehen sich auf die 15tägigen Kulturen. Die Masse der Sporen sind als Mittelwerte von 50 Messungen angegeben.

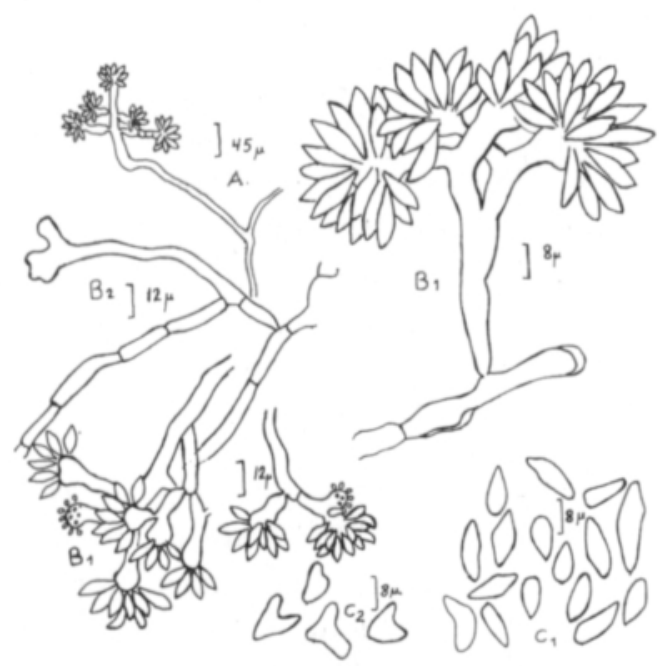

Abb. 1. B. anthophila. Konidienträger mit Sporen (A, $\left.B_{1}\right)$, Pilzmyzel (B), Konidien $\left(C_{1}\right)$, missgestalte Sporen $\left(\mathrm{C}_{2}\right)$ (15tägige SM-Agarkultur).

Auf SM-Agar, $+22^{\circ} \mathrm{C}$, ist das Wachstum des Pilzes langsam, der Durchmesser des Bestandes nach 10 Tagen $20-25 \mathrm{~mm}$; der Pilz wächst als anaerobes, submerses, septiertes, kurzzelliges (Hyphenzelle im Mittel 3-6×12 $\mu$ ) Myzel, aus dem im mittleren Teil in reichlichem Masse Konidienträger aufragen; diese nebst Sporen verleihen dem Bestande eine hell-graubraune Farbe. Die Konidienträger sind gerade oder etwas geschlängelt (Abb. $1 \mathrm{~A}$, und 2), von wechselnder Länge, $80-200 \mu$, zuweilen bis $500 \mu$ lang, an ihrem oberen Ende etwas verdickt, im Querschnitt $5-8 \mu$, verzweigt; von den Nebenästen gehen $1-5$ kurze, keulenförmige, meist in einer zweiköpfigen Verdickung endigende Zweige ab; an diesen entwickeln sich ungestielte, 


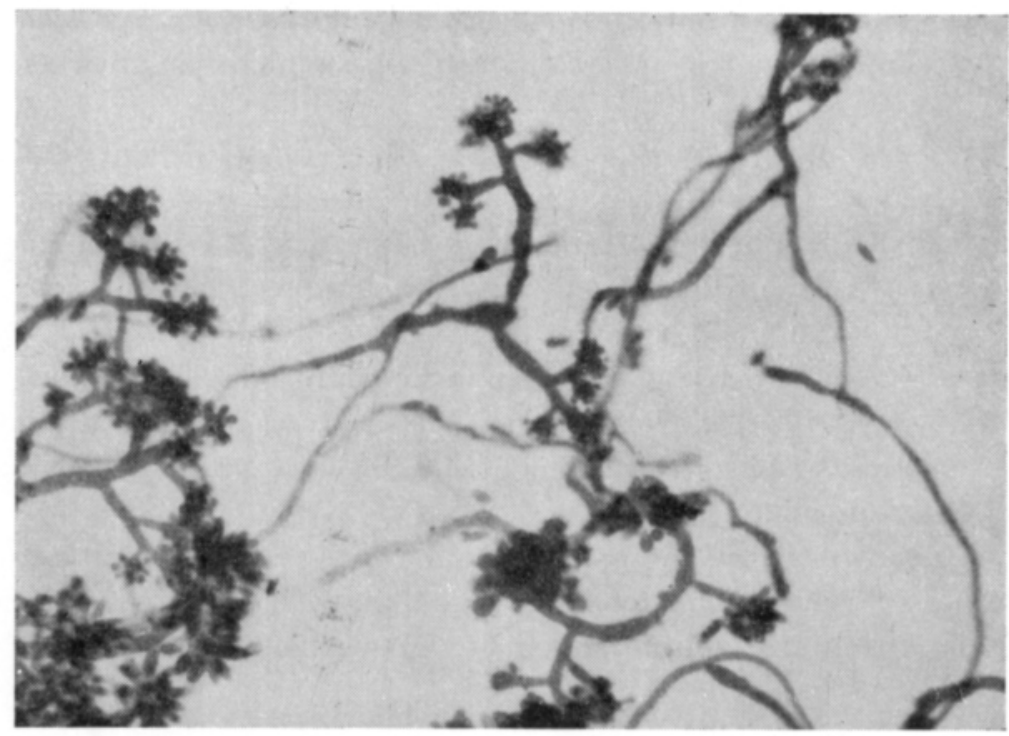

Abb. 2. Konidienträger von Botrytis anthophila, mit Sporen, aus 15tägiger SM-Kultur (Methylenblaufärbung).

einzellige, länglich-eiförmige bis spindelförmige, fast hyaline Konidien, mittlere Sporenmasse $12.5 \times 4.4 \mu(7.5-18.0 \times 3.0-6.0 \mu)$, indem sie traubenförmige Gruppen von 18-20 Sporen bilden. Missgestalte Sporen (Abb. 1, C 2) kommen in gewissem Masse vor. Die Sporen der submersen Konidienträger sind annähernd rund; deren bilden sich verhältnismässig wenig. Mikrokonidien und Sklerotien sind in einmonatigen Kulturen nicht vorgekommen. Die Messungsergebnisse entsprechen den im Schrifttum für $B$, anthophila dargestellten Angaben. Auf autoklavisierten Mohrrübenscheiben, $+22^{\circ} \mathrm{C}$, wuchs der Pilz sehr gut. Bei $5^{\circ} \mathrm{C}$ das Wachstum des Pilzes langsam; Durchmesser des Bestandes nach einem Monat etwa $10 \mathrm{~mm}$.

In Probenmengen aus folgenden Ortschaften fand sich denn auch B. anthophila; die Zahlen der Zusammenstellung geben an, wieviel \% vom Samen der Probenmenge von dem Pilz befallen waren:

$A b$. Perniö 3.0; Salo 2.0; Yläne 10.0.

$N$. Helsinki 8.5 ; Inkoo 6.5; Järvenpää: Probe a) 14.5 ; b) 2.0 .

St. Humppila 2.0; Kauvatsa 20.5; Kiukainen 4.0; Lauttala 4.0; Pori 7.5; Vammala 2.5.

Ta. Forssa: Probe a) 2.0, b) 2.5, c) 2.5, d) 1.5, e) 2.0; Hämeenlinna 12.5; Jokioinen: Probe a) 4.0, b) 10.5; Lahti 3.0; Riihimäki 2.0; Toijala 6.0; Valkeakoski 10.5 .

Ka. Inkeroinen 10.5; Kotka: Probe a) 4.0, b) 4.0.

Sb. Rautalampi 8.0 .

Oa. Lapua 10.5; Nurmo: Probe a) 5.5, b) 4.0; Ylistaro 6.0.

Botrytis anthophila scheint also in Finnland allgemein zu sein. Dieser Pilz kann durch die Saatgut von Ort zu Ort verbreiten. 
Aus Samenproben vom südlichen und mittleren Finnland wurde ein Pilz Botrytis anthophila Bond. isoliert, der die Staubbeutel von Rotklee vernichtet. Dieser Pilz ist nicht früher in Finnland gefunden worden. Nach Literatur hat er einen schädlichen Einfluss auf die Samenernte von Rotklee.

\title{
LITERATUR
}

(1) Aleshina, O. 1957. Flower mildew on clover in the Murmansk distrct. J. Pl. Prot., Moscow, 3: 44 (Ref. Rev. Appl. Myc. 37: 592).

(2) BergströM, INGrid 1940. Ståndargråmögel, Botrytis anthophila Bond. - en i Sverige tidigare ej uppmärksammad parasitsvamp på rödklöver. Växtskyddsnot., $57-59$.

(3) van Beyma Thое Kingma, F. H. 1927. Ueber eine Botrytisart von Rotkleesamen. Meded. Phytopath. Lab. W. C. Scholten, X: 37-41 (Ref. Rev. Appl. Myc. 6: 489).

(4) Bondarcev, A. C. 1914. Eine neue Krankheit der Blüten des Rotklees in Zusammenhange mit seiner Fruktifikation J. bolešn. rast. 8: 1-25 (Ref. Z. f. Pfl. Krheit 25: 367).

(5) Hardison, J. R. 1948. Occurence of anther mold in Ladino clover in Oregon. Plant Dis. Reptr. 32: 242 .

(6) JAczewski, A. A. 1916. Fungous and bacterial diseases of clover. Dep. Agric. Bur. Myc. and Phytopath. Sci Comm. Publ. 1-64. Tula (Ref. Noble M. 1948).

(7) Lовıк, A. J. 1922. The effect of,parasitic fungi on clover crops. J. bolešn. rast. 11: 2-8 (Ref. Silow 1933).

(8) Meier, A. A. \& Krivodubskaya, N. I. 1939. Methods for controlling the anther mould of Red Clover. Bull. Pl. Prot. Leningr. 1: 125-129 (Ref. Rev. Appl. Myc. 19: 415).

(9) Noble, Mary 1948. Seed-borne diseases of clover. Trans. Brit. Myc. Soc. 30: 84-91.

(10) Schlecht, F. 1921. Untersuchungen über die Befruchtungsverhältnisse bei Rotklee. Z. Pfl. Zücht. 8: $152-157$.

(11) Sigrianski, A. M. \& Minyaeva, O. M. 1937. Summary of the scientific research work of the Institute of Plant Protection for the year 1936. Part II. Pests and diseases of industrial and fruit crops. 339-341 (Ref. Rev. Appl. Myc. 17: 438-441).

(12) Silow, R. A. 1933. A systemic disease of red clover caused by Botrytis anthophila Bond. Trans Brit. Myc. Soc. 18: 239-248.

(13) Trousova, N. P. 1926. Fungus Diseases of Red Clover, Moskau (Ref. Rev. Appl. Myc. 6: 98).

\section{SELOST U S:}

\section{BOTRYTIS ANTHOPHILA BOND.:IN ESIINTYMISESTÅ SUOMALAISEN PUNA-APILAN KAUPPASIEMENNÄYTTEISS $\AA$}

\author{
Arvi Salonen \\ Helsingin yliopiston kasvipatologian laitos
}

Etelä- ja Keski-Suomesta saaduista siemennäytteistä eristettiin puna-apilan heteitä tuhoava sieni, Botrytis anthophila Bond., jota ei aikaisemmin ole havaittu Suomessa esiintyvän. Kirjallisuuden mukaan se vaikuttaa haitallisesti puna-apilan siemensadon määrään. 